\title{
Is height a risk factor for colorectal adenoma?
}

\author{
Jeung Hui Pyo, Sung Noh Hong, Byung-Hoon Min, Dong Kyung Chang, Hee Jung Son, \\ Poong-Lyul Rhee, Jae J. Kim, and Young-Ho Kim
}

Division of Gastroenterology, Department of Medicine, Samsung Medical Center, Sungkyunkwan University School of Medicine, Seoul, Korea

\author{
Received: October 16, 2014 \\ Revised : December 6, 2014 \\ Accepted: January 8, 2015

\section{Correspondence to} \\ Young-Ho Kim, M.D. \\ Division of Gastroenterology, De- \\ partment of Medicine, Samsung \\ Medical Center, Sungkyunkwan \\ University School of Medicine, \\ 81 Irwon-ro, Gangnam-gu, Seoul \\ 06351, Korea \\ Tel: +82-2-3410-3409 \\ Fax: $+82-2-3410-6983$ \\ E-mail: bowelkim@gmail.com
}

Background/Aims: Although it is generally known that the risk for all types of cancer increases with adult height, combined and for several common site-specific cancers (including colon and rectal), evidence is limited for adenomas, which are precursors to colorectal cancer. We evaluated the association between height and risk of colorectal adenoma at various stages of the adenoma-carcinoma pathway.

Methods: We conducted a retrospective study using data from patients who had undergone a complete colonoscopy as part of a health examination at the Health Promotion Center of Samsung Medical Center between October 13, 2009 and December 31, 2011. A total of 1,347 male subjects were included in our study. Multivariate logistic regression analysis was used to evaluate the association between height and colorectal adenoma.

Results: Each 5-cm increase in height was associated with 1.6\% and 5.3\% higher risks of advanced colorectal adenoma and high-risk colorectal adenoma, respectively, but associations were not significant after adjusting for age, body mass index, metabolic syndrome, alcohol intake, smoking, family history of colorectal cancer, and regular aspirin use ( $p=0.840$ and $p=0.472$, respectively).

Conclusions: No clear association was found between colorectal adenoma risk and height. Unlike other site-specific tumors reported to have a consistent relationship with height, the association between colorectal tumor and height remains controversial.

Keywords: Body height; Colorectal adenoma; Colorectal neoplasms; Body weight

\section{INTRODUCTION}

Tall people face an increased risk for cancer. The increased risk of cancer associated with increased adult height has been reported for all cancers combined and for several specific common cancers, such as breast, ovary, prostate, and large bowel [1-3]. However, evidence is limited for associations between height and risk of precancerous lesions, including colorectal adenoma, the major target of colorectal cancer (CRC) prevention by colonoscopy.

Colorectal adenomas, the precursors of almost all sporadic CRCs, are found in up to $40 \%$ of people $>60$ years of age [4]. The adenoma-carcinoma sequence, representing the progression from normal colonic mucosa to small tubular adenomas to larger adenomas and, in those with more advanced histological features (villous features, high-grade dysplasia, or both), to cancer, is a central tenet of our understanding and management of colonic adenomas [4]. Endoscopic removal of adenomas reduces the incidence of CRC [5]. Evaluating the risk factors for colorectal adenoma and eliminating them or increasing screening for those at risk could be helpful to prevent CRC. 
Moreover, it is unclear to what extent height-associated risks vary by adenoma size, number, and histological type, or how other factors, such as smoking and metabolic syndrome, affect these associations. One study showed that height may be an explanatory factor for the sex difference in human cancers [6]. CRC occurs more frequently in men, and this excess risk may be due, in part, to factors associated with height (e.g., number of susceptible cells in a specific organ or growth-influencing exposure during childhood).

The aim of this study was to evaluate the association between height and risk for colorectal adenoma. We investigated a cohort of Korean men, as sex difference affects the association between height and risk for CRC.

\section{METHODS}

\section{Study participants}

The study participants were Korean men (20 to 85 years of age) at baseline, who had undergone a complete colonoscopy as part of a health examination at the Health Promotion Center of Samsung Medical Center between October 13, 2009 and December 31, 2011. A total of 1,347 male subjects were included.

\section{Measurements}

Weight $(\mathrm{kg})$ and height $(\mathrm{cm})$ were measured in light clothing using a standardized scale and stadiometer, respectively, by registered nursing staff. The mean height of the study participants was $170.1 \mathrm{~cm}$ (standard deviation, $5.75 \mathrm{~cm}$; range, 142.6 to $190.8 \mathrm{~cm}$ ). Body mass index (BMI) was calculated as weight divided by height squared (weight $[\mathrm{kg}] /$ height $\left[\mathrm{m}^{2}\right]$ ). Information on the health-related behaviors of all participants was obtained by self-administered questionnaire. Three categories were constructed for smoking habits in men, including never smoker, former smoker, and current smoker. Metabolic syndrome was evaluated as defined by the National Cholesterol Education Program Adult Treatment Panel III. Metabolic syndrome was diagnosed when three or more of the following criteria were met:(1) BM I $\geq 25 \mathrm{~kg} / \mathrm{m}^{2}$; (2) triglycerides (TG) $\geq 150 \mathrm{mg} / \mathrm{dL}$ or on drug treatment to decrease TG; (3) high density lipoprotein cholesterol $(\mathrm{HDL}-\mathrm{C})<40 \mathrm{mg} / \mathrm{dL}$ or on drug treatment to reduce HDL-C; (4) blood pressure $\geq 130 / 85 \mathrm{mmHg}$, or on drug treatment for hypertension; and (5) fasting blood sugar $\geq 110 \mathrm{mg} / \mathrm{dL}$, or on drug treatment to decrease blood glucose. Regular aspirin use was defined as consumption of two or more aspirin tablets per week for the last 12 months.

\section{Outcome measurements}

The main endpoint was the association between height and risk of colorectal adenoma. A complete colonoscopy (Evis Lucera spectrum CLV-260SL Light Source, Olympus, Tokyo, Japan) was performed on each patient between October 13, 2009 and December 31, 2011. Twenty-two board-certified gastroenterologists performed the colonoscopies. All colonoscopists had performed less than 500 examinations before the study period or before working at the Center for Health Promotion. Colonoscopies were performed after bowel preparation with $4 \mathrm{~L}$ polyethylene glycol solution (Colyte, Taejun, Seoul, Korea; Colyte-F, Taejun; Colonlyte, Dreampharma, Seoul, Korea). A complete colonoscopic examination was regarded as cecal intubation and adequate bowel preparation. The characteristics of adenomas, including number, size, and pathology, were documented. The pathological diagnosis and definition of colorectal adenoma were based on the World Health Organization classification [7]. All specimens were diagnosed with histological descriptions by pathologists. Advanced colorectal adenoma was defined as any of the following: (1) adenoma $\geq 10 \mathrm{~mm}$; (2) villous histology; or (3) highgrade dysplasia. High-risk adenomas were defined as advanced adenomas or three or more adenomas. The primary endpoint of this study was adenoma number. Secondary endpoints were the numbers of advanced adenomas and high-risk adenomas. Colorectal adenoma subsites were categorized into right-sided (from cecum to splenic flexure) or left-sided (from descending colon to rectum). Adenomas with overlapping lesions in the colon or that were not otherwise specified were excluded from analysis.

\section{Analytical methods}

The risk for colorectal adenoma associated with each 5 -cm increase in height, and with quartiles of height among study participants, were estimated by logistic regression analysis in participants with complete anthropometric and lifestyle factor data. Covariates were 
adjusted using multivariate logistic regression analysis to examine the effect of potential confounders on the association between height and colorectal adenoma. We adjusted for age, BMI, metabolic syndrome, family history of CRC, smoking, alcohol intake, and regular aspirin intake. All statistical calculations were performed using the SAS version 9.3 (SAS Institute Inc., Cary, NC, USA). The $p$ values $<0.05$ were significant. The statistical analysis was conducted in consultation with biomedical statisticians at Samsung Medical Center.

\section{RESULTS}

Of the 1,347 men included, 618 (45.9\%) had colorectal adenomas, 56 (4.2\%) had advanced adenomas, and 175 (13.0\%) had high-risk adenomas.

We compared the distribution of risk factors according to height quartiles among participants. Taller individuals were younger $(p=0.033$ ) (Table 1 ). Comparisons of subjects with colorectal adenomas and those without adenomas, as well as the risk factor distribution (Table 2), revealed that those who developed colorectal adenomas were significantly more likely to be older than those who did not $(p<0.001)$. However, no significant association was observed among the other risk factors.

We also compared the associations between risk factors and risk of adenoma according to subsite (Table 3). After adjusting for age, no significant association was observed between risk factors (including height) and right-sided or left-sided adenomas, except for smoking, which was significantly associated with all adenomas and left-sided adenomas.

We examined the association between height and colorectal adenoma risk in men. In the age-adjusted analysis (Table 4), each 5-cm increase in height was associated with a $1.5 \%$ higher risk for advanced colorectal adenoma and a 5.6\% higher risk of high-risk adenoma, but no increased risk was detected for all types of adenomas. Advanced and high-risk adenomas (1.6\% and 5.3\%, respectively) tended to be associated after additional adjustments for potential confounding factors $(p=0.840$ and $p=0.472$, respectively).

\section{DISCUSSION}

Height and cancer risk have been reported to be either positively or negatively associated in a number of studies [1-3]. Taller individuals appear to be at increased risk for cancer. One study reported a robust positive association between height and mortality from allsites-combined cancer in a Korean male cohort study [8].

The association between height and site-specific cancer risk is inconsistent among studies, compared to all-site cancer risk. More studies have reported no height-cancer associations for CRC compared to those reporting a positive association. One meta-analysis [1]

Table 1. Baseline characteristics of the study participants

\begin{tabular}{|c|c|c|c|c|c|}
\hline \multirow{2}{*}{ Characteristic } & \multicolumn{4}{|c|}{ Height quartile, $\mathrm{cm}$} & \multirow{2}{*}{$p$ value } \\
\hline & $\leq 166.3(n=340)$ & $166.4-170(n=336)$ & $170.1-173.9(n=327)$ & $\geq 174(\mathrm{n}=344)$ & \\
\hline Age, yr & $59 \cdot 9(40-83)$ & $58.5(39-78)$ & $58.5(38-84)$ & $58.0(29-80)$ & 0.033 \\
\hline $\mathrm{BMI}, \mathrm{kg} / \mathrm{m}^{2}$ & $24.8(15.6-35.7)$ & $24.6(15.4-32.4)$ & $24.4(16.8-32.3)$ & $24.4(16.7-43.6)$ & 0.099 \\
\hline Metabolic syndrome & $66(19.4)$ & $73(21.7)$ & $65(19.9)$ & $91(26.5)$ & 0.103 \\
\hline Alcohol intake & $283(83.2)$ & $291(86.6)$ & $282(86.2)$ & $302(87.8)$ & 0.364 \\
\hline Smoking habit & & & & & 0.658 \\
\hline Never & $87(26.1)$ & $71(20.6)$ & $68(20.2)$ & $81(23.2)$ & \\
\hline Past & $161(47.5)$ & $157(48.0)$ & $155(48.7)$ & $162(47.1)$ & \\
\hline Current & $92(26.4)$ & $108(31.3)$ & $104(31.0)$ & $101(29.6)$ & \\
\hline Family history of CRC & $18(5 \cdot 3)$ & $13(3 \cdot 9)$ & $11(3.4)$ & $17(4 \cdot 9)$ & 0.582 \\
\hline Regular use of aspirin & $73(21.7)$ & $54(16.2)$ & $63(18.0)$ & $65(18.5)$ & 0.356 \\
\hline
\end{tabular}

Values are presented as median (range) or number (\%).

BMI, body mass index; CRC, colorectal cancer. 
Table 2. Comparison of risk factor distributions between subjects with and without colorectal adenoma

\begin{tabular}{|c|c|c|c|}
\hline Variable & $\begin{array}{l}\text { Subjects without adenoma } \\
\qquad(\mathrm{n}=729)\end{array}$ & $\begin{array}{l}\text { Subjects with adenoma } \\
\qquad(\mathrm{n}=618)\end{array}$ & $p$ value \\
\hline Age, yr & $56.9(48.4-65.4)$ & $60.9(51.9-69.9)$ & $<0.001$ \\
\hline Height quartile, group & & & 0.208 \\
\hline 1 & 177 & 163 & \\
\hline 2 & 181 & 155 & \\
\hline 3 & 177 & 150 & \\
\hline 4 & 194 & 150 & \\
\hline Body mass index, kg/m² & $24.5(21.9-27.1)$ & $24.7(22.0-27.4)$ & 0.291 \\
\hline Metabolic syndrome & $152(20.9)$ & $143(23.1)$ & 0.227 \\
\hline Smoking habit & & & 0.383 \\
\hline Never & $171(23.4)$ & $136(22.0)$ & \\
\hline Past & $347(47 \cdot 6)$ & $288(46.6)$ & \\
\hline Current & $211(28.9)$ & $194(31.4)$ & \\
\hline Alcohol intake & $634(87.0)$ & $524(0.85)$ & 0.501 \\
\hline Family history of CRC & $35(4.8)$ & $24(38.8)$ & 0.894 \\
\hline Regular intake of aspirin & $124(17.0)$ & $131(21.2)$ & 0.291 \\
\hline
\end{tabular}

Values are presented as median (range) or number (\%).

CRC, colorectal cancer.

summarized the results of 16 prospective studies that reported on the associations between height and CRC; nine of the studies reviewed reported no association between height and cancer risk. In addition, in a review of 13 case-control studies reporting on height-CRC associations [9-21], 10 reported no height-cancer association [10,12-14,16-21], whereas three reported an increased risk (odds ratios [ORs] > 1.2) for taller individuals [9,11,15]; however, these effects were not significant at $p<0.05$. In contrast, a meta-analysis of 13 case-controlled studies [22] with a combined total of 5,287 CRC cases reported a consistent height-cancer association in males. As inconsistent data have been reported in previous studies, the potential height-CRC association remains controversial.

Despite the large amount of research on the potential association between height and CRC risk, no study has evaluated the association between height and colorectal adenoma. We assessed the relationship between height and colorectal adenoma in a case-control study among participants undergoing routine colonoscopy. Considering that colorectal adenomas are the precursors of almost all cases of sporadic CRC, and are the target of colonoscopic screening (which is highly effective for preventing $\mathrm{CRC}$ ), evaluating the association between height and colorectal adenoma is clinically important.

This cohort study of Korean men shows a clear, but not significant trend of increasing risk of advanced adenoma and high-risk adenoma with increasing height ([OR, 1.015; 95\% confidence interval [CI], 0.874 to 1.18o; $p$ $=0.845]$ and [OR, 1.056; $95 \%$ CI, 0.918 to $1.214 ; p=0.449$ ], respectively). The risk for all adenomas did not increase in accordance with height. Compared to all-site cancer risk, the height-CRC association is more controversial. We found no association between height and colorectal adenoma; thus, colorectal tumor risk had no association with height, whereas other site-specific tumors have been consistently reported to have associations with height, such as breast cancer. The reasons for the differences in risk among different tumors, and their association with height, have not been fully explained.

A possible explanation for the discrepancy in findings between colorectal tumors and other types of tumors in association with height include the relationship between height and intestinal length. It has been suggested that taller individuals have larger organs and therefore a greater number of cells that can undergo neoplastic change at each of these sites. This finding has been proposed for the height and CRC association, because taller 
Table 3. Association between risk factors and colorectal adenomas according to subsite

\begin{tabular}{|c|c|c|c|}
\hline Variable & $\begin{array}{l}\text { All subjects with adenoma } \\
\qquad(\mathrm{n}=618)\end{array}$ & $\begin{array}{c}\text { Subjects with right-sided } \\
\text { adenoma only }(\mathrm{n}=285)\end{array}$ & $\begin{array}{l}\text { Subjects with left-sided } \\
\text { adenoma only }(\mathrm{n}=157)\end{array}$ \\
\hline Age & $1.058(1.044-1.072)$ & $1.053(1.035-1.072)$ & $1.042(1.020-1.064)$ \\
\hline$p$ trend & $<0.001$ & $<0.001$ & $<0.001$ \\
\hline \multicolumn{4}{|l|}{ Height quartile, group } \\
\hline 1 & 1.0 (reference) & 1.0 (reference) & 1.0 (reference) \\
\hline 2 & $0.992\left(0.725^{-1.356)}\right.$ & $1.147(0.767-1.718)$ & $0.608(0.369-0.999)$ \\
\hline 3 & $0.989(0.722-1.355)$ & $1.312(0.880-1.957)$ & $0.635(0.388-1.038)$ \\
\hline 4 & $0.928(0.679-1.270)$ & $1.093(0.729-1.638)$ & $0.731\left(0.45^{8-1.167)}\right.$ \\
\hline p trend & 0.965 & 0.597 & 0.162 \\
\hline Body mass index, $\mathrm{kg} / \mathrm{m}^{2}$ & $1.034(0.989-1.080)$ & $1.059(1.000-1.122)$ & $1.005(0.937-1.077)$ \\
\hline ptrend & 0.141 & 0.052 & 0.888 \\
\hline \multicolumn{4}{|l|}{ Metabolic syndrome } \\
\hline No & 1.0 (reference) & 1.o (reference) & 1.0 (reference) \\
\hline Yes & $1.005(0.758-1.333)$ & $0.963(0.674-1.377)$ & $0.665(0.407-1.087)$ \\
\hline$p$ trend & 0.971 & 0.837 & 0.104 \\
\hline \multicolumn{4}{|l|}{ Family history of CRC } \\
\hline No & 1.0 (reference) & 1.o (reference) & 1.0 (reference) \\
\hline Yes & $0.841(0.486-1.455)$ & $0.834(0.418-1.661)$ & $1.000(0.447-2.237)$ \\
\hline$p$ trend & 0.536 & 0.605 & 0.999 \\
\hline \multicolumn{4}{|l|}{ Smoking habit } \\
\hline Never & 1.0 (reference) & 1.0 (reference) & 1.0(reference) \\
\hline Past & $1.083(0.805-1.458)$ & $1.002(0.690-1.455)$ & $1.187(0.725-1.942)$ \\
\hline Current & $1.490\left(1.075^{-2.065)}\right.$ & $1.092(0.718-1.661)$ & $1.819(1.081-3.059)$ \\
\hline ptrend & 0.023 & 0.872 & 0.040 \\
\hline \multicolumn{4}{|l|}{ Alcohol intake } \\
\hline No & 1.0 (reference) & 1.0 (reference) & 1.0 (reference) \\
\hline Yes & $1.015(0.722-1.428)$ & $1.154(0.740-1.801)$ & $0.805(0.477-1.356)$ \\
\hline ptrend & 0.930 & 0.528 & 0.414 \\
\hline \multicolumn{4}{|l|}{ Regular use of aspirin } \\
\hline No & 1.0 (reference) & $1.0($ reference $)$ & 1.0 (reference) \\
\hline Yes & $1.026(0.767-1.374)$ & $1.028(0.712-1.485)$ & $1.026(0.643-1.638)$ \\
\hline$p$ trend & 0.862 & 0.883 & 0.913 \\
\hline
\end{tabular}

Values are presented as odd ratio (95\% confidence interval).

CRC, colorectal cancer.

people have longer intestinal tracts (and, therefore, increased epithelial cell proliferation) [23] and also because acromegaly has been associated with an increased risk for CRC [24]. However, it is unclear whether increased height always results in a commensurate increase in intestinal length, surface area, or cell number. Intestinal length is roughly correlated with sex, age, weight, height, and racial origin [25]. In a study by Hounnou et al. [26], 200 non-fixed adult cadavers were studied, and the length of the entire intestine was correlated with subject weight, but not height. A multivariate analysis demonstrated that body weight had the strongest correlation with intestinal length, not height. Compelling evidence from epidemiological studies indicates that elevated levels of insulin like growth factor-1, insulin resistance, and associated complications, such as ele- 
Table 4. Association between height and colorectal adenoma risk in men

\begin{tabular}{|c|c|c|c|c|c|c|}
\hline \multirow{2}{*}{ Variable } & \multicolumn{4}{|c|}{ Height quartile, group } & \multirow{2}{*}{ 5-cm increment } & \multirow{2}{*}{$p$ value } \\
\hline & 2 & 3 & 4 & $p$ value & & \\
\hline \multicolumn{7}{|l|}{ All adenoma } \\
\hline Age-adjusted & $\begin{array}{c}1.001 \\
(0.734-1.365)\end{array}$ & $\begin{array}{c}0.990 \\
\left(0.725^{-1.353)}\right.\end{array}$ & $\begin{array}{c}0.919 \\
(0.674-1.252)\end{array}$ & 0.939 & $\begin{array}{c}0.966 \\
(0.877-1.063)\end{array}$ & 0.479 \\
\hline Multivariate-adjusted $^{\mathrm{a}}$ & $\begin{array}{c}0.991 \\
\left(0.725^{-1.354)}\right.\end{array}$ & $\begin{array}{c}0.988 \\
(0.721-1.353)\end{array}$ & $\begin{array}{c}0.928 \\
(0.679-1.269)\end{array}$ & 0.965 & $\begin{array}{c}0.969 \\
(1.040-1.066)\end{array}$ & 0.527 \\
\hline \multicolumn{7}{|l|}{ Advanced adenoma } \\
\hline Age-adjusted & $\begin{array}{c}1.327 \\
(0.814-2.163)\end{array}$ & $\begin{array}{c}1.234 \\
(0.749-2.034)\end{array}$ & $\begin{array}{c}1.009 \\
(0.605-1.683)\end{array}$ & 0.589 & $\begin{array}{c}1.015 \\
(0.874-1.180)\end{array}$ & 0.845 \\
\hline Multivariate-adjusted $^{\mathrm{a}}$ & $\begin{array}{c}1.300 \\
(0.793-2.129)\end{array}$ & $\begin{array}{c}1.231 \\
(0.744-2.039)\end{array}$ & $\begin{array}{c}1.015 \\
(0.606-1.702)\end{array}$ & 0.650 & $\begin{array}{c}1.016 \\
(0.873-1.183)\end{array}$ & 0.840 \\
\hline \multicolumn{7}{|l|}{ High-risk adenoma } \\
\hline Age-adjusted & $\begin{array}{c}1.437 \\
(0.908-2.275)\end{array}$ & $\begin{array}{c}1.320 \\
(0.826-2.112)\end{array}$ & $\begin{array}{c}1.174 \\
(0.732-1.885)\end{array}$ & 0.448 & $\begin{array}{c}1.056 \\
(0.918-1.214)\end{array}$ & 0.449 \\
\hline Multivariate-adjusted $^{\mathrm{a}}$ & $\begin{array}{c}1.417 \\
(0.892-2.252)\end{array}$ & $\begin{array}{c}1.325 \\
(0.826-2.126)\end{array}$ & $\begin{array}{c}1.169 \\
(0.726-1.884)\end{array}$ & 0.479 & $\begin{array}{c}1.053 \\
(0.914-1.213)\end{array}$ & 0.472 \\
\hline
\end{tabular}

Values are presented as odd ratio (95\% confidence interval).

${ }^{a}$ Adjusted for age, smoking, alcohol intake, body mass index, metabolic syndrome, regular use of aspirin, and family history of colorectal cancer.

vated fasting plasma glucose, glucose intolerance, increased BMI, and metabolic syndrome, are associated with an increased risk for CRC $[27,28]$. Therefore, previous studies that showed a positive association between height and CRC may, in fact, be showing a relationship with body weight rather than height. Sadahiro et al. [25] studied 920 Japanese patients who underwent barium enemas and demonstrated that colon length tended to increase with body dimensions in women, but was not specifically correlated with the weight or height of the subjects.

A few limitations of this study should be mentioned. Because the range of height in a given population is usually narrow, large numbers of events are needed to reliably eliminate risk. We included 1,347 cases, in which the incidence of colorectal adenoma was 45.9\%; hence, our results may have limited statistical power to study the height-colorectal adenoma risk.

In conclusion, no clear association was found between colorectal adenoma and height in adults, as reported for CRC. A larger scale prospective validation study is needed to assess the association between colorectal tumor and height.

\section{KEY MESSAGE}

1. The increased risk of cancer associated with increased adult height has been reported for all cancers as a whole and for several specific common cancers, including colorectal cancers.

2. However, evidence is limited for the associations between height and the risk of colorectal adenoma, the precursors of almost all sporadic colorectal cancers.

3. There is no clear association between colorectal adenoma and height.

\section{Conflict of interest}

No potential conflict of interest relevant to this article was reported.

\section{Acknowledgments}

This study was supported by a National Research Foundation of Korea grant, funded by the Korean government (MEST) (no. 2011-0016178). 


\section{REFERENCES}

1. Gunnell D, Okasha M, Smith GD, Oliver SE, Sandhu J, Holly JM. Height, leg length, and cancer risk: a systematic review. Epidemiol Rev 2001;23:313-342.

2. Batty GD, Shipley MJ, Langenberg C, Marmot MG, Davey Smith G. Adult height in relation to mortality from 14 cancer sites in men in London (UK): evidence from the original Whitehall study. Ann Oncol 2006;17:157-166.

3. Pischon T, Lahmann PH, Boeing $\mathrm{H}$, et al. Body size and risk of colon and rectal cancer in the European Prospective Investigation Into Cancer and Nutrition (EPIC). J Natl Cancer Inst 2006;98:920-931.

4. Levine JS, Ahnen DJ. Clinical practice: adenomatous polyps of the colon. N Engl J Med 2006;355:2551-2557.

5. Winawer SJ, Zauber AG, Ho MN, et al. Prevention of colorectal cancer by colonoscopic polypectomy: the National Polyp Study Workgroup. N Engl J Med 1993;329:1977-1981.

6. Walter RB, Brasky TM, Buckley SA, Potter JD, White E. Height as an explanatory factor for sex differences in human cancer. J Natl Cancer Inst 2013;105:860-868.

7. Hamilton SR, Aaltone LA. Tumors of the colon and rectum. In: Aaltone LA, Hamilton SR; World Health Organization; International Agency for Research on Cancer, eds. Pathology and Genetics of Tumors of the Digestive System. Lyon: IARC Press, 2000:103-143.

8. Song YM, Smith GD, Sung J. Adult height and cause-specific mortality: a large prospective study of South Korean men. Am J Epidemiol 2003;158:479-485.

9. Caan BJ, Coates AO, Slattery ML, Potter JD, Quesenberry CP Jr, Edwards SM. Body size and the risk of colon cancer in a large case-control study. Int J Obes Relat Metab Disord 1998;22:178-184.

10. Dales LG, Friedman GD, Ury HK, Grossman S, Williams SR. A case-control study of relationships of diet and other traits to colorectal cancer in American blacks. Am J Epidemiol 1979;109:132-144.

11. Dietz AT, Newcomb PA, Marcus PM, Storer BE. The association of body size and large bowel cancer risk in Wisconsin (United States) women. Cancer Causes Control 1995;6:30-36.

12. Freudenheim JL, Graham S, Marshall JR, Haughey BP, Wilkinson G. A case-control study of diet and rectal cancer in western New York. Am J Epidemiol 1990;131:612-624.

13. Higginson J. Etiological factors in gastrointestinal cancer in man. J Natl Cancer Inst 1966;37:527-545.

14. Jain M, Cook GM, Davis FG, Grace MG, Howe GR, Miller
AB. A case-control study of diet and colo-rectal cancer. Int J Cancer 1980;26:757-768.

15. La Vecchia C, Negri E, Parazzini F, et al. Height and cancer risk in a network of case-control studies from northern Italy. Int J Cancer 1990;45:275-279.

16. Le Marchand L, Wilkens LR, Kolonel LN, Hankin JH, Lyu LC. Associations of sedentary lifestyle, obesity, smoking, alcohol use, and diabetes with the risk of colorectal cancer. Cancer Res 1997;57:4787-4794.

17. Manousos O, Souglakos J, Bosetti C, et al. IGF-I and IGFII in relation to colorectal cancer. Int J Cancer 1999;83:1517.

18. Papadimitriou C, Day N, Tzonou A, Gerovassilis F, Manousos O, Trichopoulos D. Biosocial correlates of colorectal cancer in Greece. Int J Epidemiol 1984;13:155-159.

19. Peters RK, Garabrant DH, Yu MC, Mack TM. A case-control study of occupational and dietary factors in colorectal cancer in young men by subsite. Cancer Res 1989;49:54595468.

20. Russo A, Franceschi S, La Vecchia C, et al. Body size and colorectal-cancer risk. Int J Cancer 1998;78:161-165.

21. Weiss NS, Daling JR, Chow WH. Incidence of cancer of the large bowel in women in relation to reproductive and hormonal factors. J Natl Cancer Inst 1981;67:57-60.

22. Howe GR, Aronson KJ, Benito E, et al. The relationship between dietary fat intake and risk of colorectal cancer: evidence from the combined analysis of 13 case-control studies. Cancer Causes Control 1997;8:215-228.

23. Ahrens EH Jr, Blankenhorn DH, Hirsch J. Measurement of the human intestinal length in vivo and some causes of variation. Gastroenterology 1956;31:274-284.

24. Ituarte EA, Petrini J, Hershman JM. Acromegaly and colon cancer. Ann Intern Med 1984;101:627-628.

25. Sadahiro S, Ohmura T, Yamada Y, Saito T, Taki Y. Analysis of length and surface area of each segment of the large intestine according to age, sex and physique. Surg Radiol Anat 1992;14:251-257.

26. Hounnou G, Destrieux C, Desme J, Bertrand P, Velut S. Anatomical study of the length of the human intestine. Surg Radiol Anat 2002;24:290-294.

27. Giovannucci E. Insulin and colon cancer. Cancer Causes Control 1995;6:164-179.

28. Moore LL, Bradlee ML, Singer MR, et al. BMI and waist circumference as predictors of lifetime colon cancer risk in Framingham Study adults. Int J Obes Relat Metab Disord 2004;28:559-567. 